\title{
Baltimore Is Burning: Can I-O Psychologists Help Extinguish the Flames?
}

\author{
Enrica N. Ruggs \\ Michelle R. Hebl \\ Rice University \\ Verónica Caridad Rabelo \\ University of Michigan \\ Kayla B. Weaver \\ Pennsylvania State University \\ Joy Kovacs \\ Kronos Incorporated \\ Andeneshea S. Kemp \\ University of South Florida
}

University of North Carolina at Charlotte

\begin{abstract}
Recent media coverage has called attention to what some see as an unreasonable use of force by law enforcement officers against unarmed Black citizens. Many of these incidents have stirred widespread concern, as there has been a large public outcry indicating that the incidents appear to have racial undertones, which is particularly pronounced given the fatal consequences that are too frequent. This article focuses on how psychological research on racial bias can explain some of the cognitive and affective processes that could be influencing law enforcement officer behavior in at least some of these incidents. Further, we discuss how industrial-organizational (I-O) psychologists can use this research and leverage current practices within the field to develop solutions and effectively deal with individual racial biases among officers within the law enforcement community. We also discuss avenues of future research within I-O psychology and hope to spark a conversation within the I-O community about additional ways the field can address tensions that have arisen between law enforcement and different communities regarding perceptions of excessive use of force by officers.
\end{abstract}

Keywords: race, bias, law enforcement, police, community

Enrica N. Ruggs, Department of Psychology, University of North Carolina at Charlotte; Michelle R. Hebl, Department of Psychology, Rice University; Verónica Caridad Rabelo, Department of Psychology, University of Michigan; Kayla B. Weaver, Department of Psychology, Pennsylvania State University; Joy Kovacs, Kronos Incorporated, Beaverton, Oregon; Andeneshea S. Kemp, Department of Psychology, University of South Florida.

Correspondence concerning this article should be addressed to Enrica N. Ruggs, Department of Psychology, University of North Carolina at Charlotte, 9201 University City Boulevard, Charlotte, NC 28223. E-mail: eruggs@uncc.edu 
As the April 2015 riots in Baltimore began over the death of Freddie Gray, the first two authors were leading a community of interest group at the annual conference for the Society for Industrial and Organizational Psychology. Ironically, our session was addressing what industrial-organizational (I-O) psychologists could and should be doing about issues like the shooting of Michael Brown by a White police officer in Ferguson, Missouri. Since that time, greater attention has been paid to countless similar events and/or deaths that have occurred involving unarmed Black men and women who are dying or being exposed to excessive force in confrontations with police officers or while in police custody. For instance, many people throughout the United States have expressed outrage about cases such as Eric Garner, the unarmed Black man whose plea of "I can't breathe" was ignored and who subsequently died in a chokehold by a New York police officer in July 2014. Additional outrage occurred with Tamir Rice, the 12-year-old Black boy holding a pellet gun who was shot and killed by an officer in Ohio in November 2014; Walter Scott, the unarmed Black man shot in the back and killed in South Carolina by an officer in April 2015; a Black female teenager, Dajerria Becton, in McKinney, Texas, who was dragged to the ground at a pool party and knelt on by an officer as she lay face down in handcuffs in June 2015; and Sandra Bland, the Black woman who allegedly committed suicide in police custody in a Waller County, Texas, jail after she was arrested following a failure to use a turning signal in July 2015 (a case in which some people have questioned the circumstances, and the potential racial bias, leading to Bland's arrest).

Although many argue that such events are not particularly unusual occurrences (and the above list is by no means exhaustive), the attention dedicated to these incidents is generating heightened awareness of deepseated race-related issues in the United States. Indeed, these incidents have highlighted and fueled racial tensions as well as minorities' fear, mistrust, outrage, and hostility toward policing throughout America. This tension was glaringly evident at the 1-year anniversary of Michael Brown's death in Ferguson on August 9, 2015. Citizens commemorating Brown's death were involved in heated interactions with law enforcement, which led to St. Louis County declaring a state of emergency in the city and surrounding areas.

We posit that in at least some of the instances where police officers use force against minority citizens, racial bias plays a role in influencing the officers' choice of behavior. In this article, we discuss ways in which research informs how and why racial bias may play a role in some of the events involving police officers shooting unarmed Black citizens as well as what I-O psychologists can do now and in the future to focus more specifically on how racial bias may influence police-citizen interactions. To do this, we start by 
defining racial bias and then review the relevant body of research that has been done in the context of, or that is related to, police forces. Next, we discuss a greater integration of the resources I-O psychologists have developed (e.g., expertise and approaches in public safety personnel selection, training, leadership) that can be leveraged to help in reducing racial biases within the law enforcement community. I-O psychologists have many tools to make a difference and frequently use these tools to create talent acquisition and talent management systems that focus on reducing and preventing racial and other biases in organizations. However, we argue that I-O psychology practitioners and researchers can do even more to specifically help reduce systematic racial biases within law enforcement.

\section{Racial Bias Defined}

Racial bias often has been defined in terms of overt (e.g., racial profiling) or subtle (e.g., implicit bias) discrimination, but these are just two of the many ways that bias toward citizens might be defined or contextualized. In the context of police officer behavior toward citizens, we define racial bias as any treatment-whether implicit or explicit, subtle or overt, or intentional or unintentional-that law enforcement personnel express toward citizens based on the citizens' race. Moreover, bias can be of both positive and negative types; here, we focus exclusively on the negative type, or that which shortchanges, restricts, devalues, and/or harms citizens. In sum, "bias-based policing" (Gove, 2011) involves the racial stereotypes, prejudice, and discrimination that some members of law enforcement possess and direct toward citizens. Individuals of all races may be victims of bias-based policing. In this article, we focus specifically on questions of police bias and violence toward Black people in the United States because this is the minority group that has been recently highlighted as the target of several perceived race-related violent incidents (see those mentioned in the opening paragraph), spurring social movements calling for change (e.g., "Black Lives Matter"; Garza, Tometi, \& Cullors, 2012). In addition, we focus on this group because most of the empirical research on racial biases focuses on Black targets.

It is important to note that we fully recognize and appreciate that law enforcement is a very difficult job in which many brave individuals risk their health and lives to ensure justice, liberty, and the safety of our citizens. We believe that a vast majority of these individuals do their job well and treat citizens of all races fairly. Furthermore, in this occupation there are instances when acts of aggression against citizens are necessary to restore order and protect communities and/or the officer involved.

However, we also know from research that bias (whether intentional or unintentional) influences decisions, and there are likely cases where some 
officers make different judgment calls about the course of action in similar situations that involve Black versus White citizens. Indeed, the FBI director James Comey has acknowledged directly the "disconnect" between police agencies and communities of color in a speech given in February $2015^{1}$ (see Horwitz, 2015). Comey suggested that police officers (whether Black or White) have a different reaction to two young men (Black vs. White) on sidewalks because Black men "look like so many others the officer has locked up" (Horwitz, 2015). Comey further stated that he doesn't know how many people (of any race) have been shot by the police because these data previously have not been reported consistently to the FBI.

In contrast to one prevalent argument, data do suggest that bias goes beyond the rationale that police simply respond differently to Blacks (vs. Whites) because Blacks commit more crimes than do Whites. For instance, in a study conducted on misdemeanor arrests in New York City (15\% of the crimes), when taking their representations within the general population into account, Blacks and Latinos were more likely than were Whites to be detained, convicted, and incarcerated for the same crime (Golub, Johnson, \& Dunlap, 2007). Other research shows that a disproportionate occurrence and intensity of force is used against Blacks compared with Whites and that Blacks are significantly more likely to be killed by police officers than are Whites (Bureau of Justice Statistics, 2011; see Correll, Hudson, Guillermo, \& Ma, 2014). As a result, states are beginning to mandate a more thorough collection of race-tagged data related to arrests, alleged brutality, and other police data (e.g., demographics related to traffic stop data, any infractions).

In the absence of consistent, objective performance criteria in law enforcement, psychologists and other scholars have examined bias from a number of different paradigms. We describe such paradigms and the associated findings, as well as the implications such results have for science and practice.

\section{Paradigms for Studying Racial Bias Related to Policing}

There are several lines of research within psychology that can be used to explain, in part, some of the cognitive and attitudinal factors that may influence incidents involving officers engaging in potentially unwarranted violence against unarmed Black citizens. In the following section, we briefly discuss research on priming, stereotyping, racial profiling, shooter bias, stereotypicality, and discrimination against Blacks in order to lay the foundation for

1 This remark was made during a speech titled Hard Truths: Law Enforcement and Race, delivered on February 12, 2015, by James Comey. The full transcript of this speech can be found on the official FBI website at https://www.fbi.gov/news/speeches/hard-truthslaw-enforcement-and-race. 
mechanisms that can play a role in law enforcement judgment and decision making about Black citizens.

\section{Priming and Stereotype Research}

There has been a longstanding association between Black individuals and perceptions of violence in the United States, and scholars have been studying this association for several decades. In one of the earliest psychology studies in this area, Allport and Postman (1947) examined people's memory for a pictorial scene on a subway in which a White man is holding a deadly razor and interacting with a Black man. People erroneously switched the race of the individuals when they recalled the event from memory. In other research, participants who watched a video of a heated argument and pushing behaviors were significantly more likely to rate the actor as engaging in violent behavior if he was Black instead of White (Duncan, 1976). Similarly, Sagar and Schofield (1980) found that sixth grade boys interpreted vaguely aggressive but innocuous behaviors (e.g., bumping in the hallway, requesting food from others, poking a student, and using another's pencil without permission) to be more threatening when displayed by Black versus White targets.

Such findings have been replicated in more crime-related paradigms. For instance, even after controlling for neighborhood crime levels, a strong positive relationship was found between the percentage of young Black men in a neighborhood and the perceptions of that neighborhood's crime level (Quillian \& Pager, 2001). Moreover, in a series of studies, Eberhardt, Goff, Purdie, and Davies (2004) found that seeing Black versus White faces led participants to more accurately detect crime-related objects that were blurred. Put in a danger alert mode by viewing Black faces, participants seemed to be on the lookout for weapons. Similarly, Eberhardt et al. also found that showing weapons made participants focus on Black faces more than on White faces. More recently, Yang, Gibson, Lueke, Huesmann, and Bushman (2014) found that participants who were primed with the race-aggression link by playing violent video games as a Black avatar displayed stronger attitudes linking Blacks to violence than those who played violent video games as a White avatar. These findings suggest that people strongly associate Blacks with aggression, crime, and violence.

\section{Racial Profiling}

Racial profiling refers to the bias that some police officers use in targeting particular individuals of a racial group as crime suspects. Although racial profiling is illegal at the federal level, legislation banning racial profiling is not always applied by local law enforcement agencies (U.S. Department of Justice, 2014). Examples of racial profiling include disproportionate rates 
when compared with Whites of pulling over Blacks for unsubstantiated reasons, asking a Black man who is simply walking down the sidewalk where he is headed, or requesting identification from a Black man who is riding a bike in a White neighborhood (or any neighborhood) - all without reasonable cause. Racial profiling has received some empirical attention. For instance, a content analysis of traffic stops in a metropolitan city in the Midwest showed that Blacks (vs. Whites) were more likely (often 3-5 times as much) to be searched, to be asked whether they had weapons, to be asked to leave the vehicle, or to have a passenger and/or vehicle searched (Dixon, Schell, Giles, \& Drogos, 2008). In addition, in an analysis of traffic violations in a large metropolitan county in the Southeast, Alpert, Dunham, and Smith (2007) found that officers were significantly more likely to conduct a background check, complete a field interview card, and conduct pat-down and vehicle searches when they stopped Black motorists compared with White motorists. These patterns of differences reveal evidence for racial profiling and have led some to use the phrase DWB, which stands for driving while Black, as a play on words for DWI (driving while intoxicated).

\section{Shooter-Bias Research}

Given that people associate Blacks more than Whites with threat, crime, and danger (Correll, Urland, \& Ito, 2006; Goff, Jackson, Di Leone, Culotta, \& DiTomasso, 2014), researchers developed a computer simulation to examine the impact that these perceptions may have on police enforcement. Using the police officer's dilemma, or shooter-bias paradigm, approximately two dozen studies have been conducted on the biases that police officers too often express toward Black versus White individuals (e.g., Correll et al., 2014; Correll, Park, Judd, \& Wittenbrink, 2002; Payne, 2001; Plant \& Peruche, 2005). In these studies, researchers manipulate the target race (Black or White) and use a videogame simulation to have participants "shoot" the armed targets and "not shoot" the unarmed ones. A meta-analysis on the shooter-bias effect showed strong evidence that participants are quicker to shoot armed Black targets, are slower to "shoot" (using split-second decisions in a simulation) unarmed Black targets, and have a stronger bias (i.e., lower shooting threshold) to shoot Black targets (compared with White targets; Mekawi \& Bresin, 2015). Participants have been more likely to express this "shooter bias" when given less time to make their decisions (Correll et al., 2002; see also Greenwald, Oakes, \& Hoffman, 2003; Payne, 2001).

When comparing shooter bias for police officers versus community members, Correll and colleagues (2007) found that police officers were better able to detect weapons and set a higher criterion in deciding when to shoot than were community members. However, both samples demonstrated racial shooter bias: Officers and citizens alike more quickly "shot" 
armed targets who were Black (vs. White) and more slowly decided to "not shoot" unarmed Black (vs. White) targets. Plant and Peruche (2005) found that certified police officers were more likely to mistakenly shoot Black versus White unarmed suspects. However, the bias decreased as officers repeated the trials, suggesting that perhaps such bias is not inevitable and can be reduced with practice or training. Plant and Peruche also found that the shooter bias was more likely to be exhibited by officers who held strong beliefs about the criminality of and/or negative attitudes toward Blacks. Taken together, the research has consistently shown a shooter bias toward Black targets and is indicative of the prevalence of racial biases.

Extending the research on race and shooter bias, Kahn and Davies (2011) found that participants (both White and Black) were more likely to shoot Black targets who were higher (vs. lower) in stereotypicality or who possessed physical features that are perceived as more typical of their racial category (Maddox, 2004). Black individuals who possess greater stereotypical features (e.g., darker skin, thick nose, coarse hair) have been perceived and treated more negatively by others (for a review, see Maddox, 2004).

\section{Subtle Discrimination Against Blacks}

Finally, studies have shown that racial biases are often very subtle. For instance, Sommers and Ellsworth (2001) had mock jurors read trial narratives about Black and White defendants. They found that when race was presented as a background characteristic (vs. making it explicitly salient), White jurors rated the Black (vs. the White) defendant as more dangerous and crime prone, and they were more likely to convict the Black (vs. the White) defendant. The researchers and others suggest that subtle racial biases have strong negative consequences for Black people, but making these biases very salient may reduce the impact of the bias tremendously and influence people to not act on them (see Devine, 1989).

Subtle racial discrimination may also be understood in the context of aversive racism. Dovidio and Gaertner (2000) defined aversive racism as a bias that occurs because people hold unconscious and implicit racial prejudices while simultaneously holding conscious, egalitarian attitudes. On the basis of this framework, people who hold egalitarian attitudes will not exhibit racial discrimination in situations where normative behavior is clear. However, when normative behavior is weak or actions can be justified by other factors besides race, individuals are more likely to exhibit subtle forms of racial bias. Evidence of aversive racism has been shown in a variety of settings. One study examining personnel selection decisions found that White decision makers recommended Black and White candidates with strong qualifications at similar rates for a position but recommended Black candidates significantly less often than White candidates when the candidates 
only had moderate (but still acceptable) qualifications (Dovidio \& Gaertner, 2000). Similarly, an experimental study involving legal decisions showed that White mock jurors did not show bias against a Black defendant (compared with a White defendant) when only admissible evidence was presented, but they were more likely to see the Black (vs. White) defendant as guilty when inadmissible yet incriminating evidence was introduced (Johnson, Whitestone, Jackson, \& Gatto, 1995).

\section{Summary of the Racial Biases Related to Policing}

Much of the research we have reviewed to this point illustrates the erroneous influence, whether intentional or unintentional, of race on perceptions and decisions about criminal status and interactions with individuals. Race often serves as an automatic cue to trigger implicit biases about individuals. For police officers (as with members of the general public), automatic cognitive processing (i.e., implicit thinking done without awareness) can serve a protective purpose, as it can guide one's behavior to avoid or remove oneself from dangerous and potentially life-threatening situations and can also guide officers to positive action. However, this automatic cognitive processing can also lead to errors in decision making that disproportionately negatively affect Black citizens.

\section{The Role of I-O Psychology in Extinguishing the Flames}

I-O psychologists have shed light on a number of different issues relevant to policing, such as personnel selection, training, and performance evaluation; however, there are many opportunities to expand work in these areas to seek greater understanding of and solutions for reducing racial biases, stereotyping, profiling, and discrimination. In the next section, we review some areas of I-O psychology that may be combined with findings from racial bias research to help detect and reduce racial bias, profiling, and unwarranted aggression in the context of police work.

\section{Personnel Selection}

One of the most widely published areas of research in I-O psychology is personnel selection, which has provided tools and procedures for reducing biases and subjectivity in selection processes, particularly as they pertain to minority groups. With regard to selecting police officers, there has been extensive work examining effective ways to reduce the adverse impact associated with differential rates of selection for different racial subgroups. This work has helped diverse job applicants experience fairer selection procedures, has minimized selection bias, and ultimately has helped increase diversity in law enforcement. In turn, more diverse law enforcement is expected to reduce racial discrimination within the ranks of police 
departments, especially within precincts with large racial/ethnic minority populations.

Although there has been progress in hiring more diverse officers, statistics show that there are communities in which the demographic makeup of the police department is vastly different from that of the surrounding community. For instance, in Baltimore 70\% of the police force is White, whereas the general population is only $50 \%$ White. Even far more striking is the fact that Whites make up $80 \%$ of the police force in Ferguson but only $25 \%$ of the general population (Ashkenas \& Park, 2015). In minority communities, the lack of demographic diversity within police forces, especially as it misaligns with the demographic diversity profile of the community, is commonly believed to fuel some of the tensions between officers and community members. It is also believed to lead to an increased prevalence of racial biases, such as the outgroup homogeneity effect whereby members of an outgroup are commonly mistaken as being characteristically the same as someone else from the same outgroup (Rubin \& Badea, 2012).

There is, in fact, much consensus that creating more balance in terms of racial similarity between law enforcement officers and citizens in the communities they serve would help improve relations between the two groups. Indeed, research has shown the positive benefits of racioethnicity matching between employees and customer bases on employee productivity and customer satisfaction (Avery, McKay, Tonidandel, Volpone, \& Morris, 2012). Thus, I-O psychologists should work with police agencies, particularly in diverse communities, to provide strategies to help attract, recruit, and screen more diverse job applicants in these areas.

When it comes to the selection of police officers, there is ample research in terms of the different traits that predict successful on-the-jobperformance, although more could be done to predict potential bias toward citizens. A meta-analysis examining the relations between selection criteria and police performance showed that cognitive ability is positively related to patrol performance and negatively related to serious officer discipline problems (Aamodt, 2004). Furthermore, cognitive ability measures developed specifically for law enforcement selection are marginally better predictors of performance than are more general cognitive ability measures (Aamodt, 2004). Other research and applied work, including job analyses, has identified several characteristics that are deemed necessary and important in order for selected people to become effective officers. Some of these characteristics include integrity, decision making, discretionary judgment, emotion regulation, stress tolerance, community relations, teamwork, physical ability, and safety (Berner, 2010; Hough, 2002). In addition, personality assessments have been useful in effectively distinguishing between topand lower-performing officers at entry levels (Detrick \& Chibnall, 2006). 
Specifically, Detrick and Chibnall found that the best entry-level officers collectively displayed significantly lower levels of Neuroticism as well as higher levels of Conscientiousness and Extraversion than did the worst performers. Personality traits of police officers have also been shown to provide favorable predictive validity for outcomes like tardiness, absenteeism, and supervisory ratings (Craig, 2005), and Conscientiousness, in particular, has been found to predict job performance in officers (Barrick \& Mount, 1991).

The factors mentioned above have been found to be important for selecting and hiring qualified law officers; however, less is known about the ability of selection procedures to predict officers' stereotype activation and application, prejudice, and discrimination against racial minorities. I-O psychologists working with law enforcement agencies can draw from the literature about racial biases to inform personnel selection procedures that help identify applicants' attitudes toward minorities, prejudices, and potential to display differential behavior toward minority (vs. nonminority) citizens. I-O psychologists can develop screening procedures that specifically assess potential for racial bias in the role. One way to do this would be to develop exercises or simulations that examine differences in behaviors or intentions to behave toward minority and nonminority citizens. In addition, situational judgment tests could be developed to gain information about applicants' judgment and decision making regarding citizens of different races. Such tests could ask applicants about the most effective response to a situation with a minority citizen and ask a similar question using a nonminority citizen. These items could be speeded (i.e., have a time restriction) to add an element of quick and spontaneous decision making. If a timed measure were used, it would be best to control for reading speed by having the scenarios administered audibly. It is important to note that information about a candidate's propensity for race bias might be used as part of the screening process in conjunction with other assessments. This information also may be used as a means to address candidates' potential proclivity toward bias during their onboarding and initial training and professional development activities.

\section{Training}

Training is another foundational area of I-O psychology. In this area, diversity, cultural, and sensitivity training are often used in part to reduce and prevent employees' biased behavior toward others. Some organizations offer sensitivity training specifically for police officers as a means of improving relations within their workplaces and with the communities they serve (e.g., the Anti-Defamation League and the Center for Policing Equity). Usually these training programs focus on providing knowledge about minority populations, communication skills for interacting with minority populations, and awareness of personally held cultural assumptions in hopes of improving 
police officer behaviors and attitudes toward minorities (Ungerleider \& McGregor, 1993). A meta-analysis found that diversity training has positive effects for a variety of outcomes, including those that are cognitive (i.e., learning, knowledge), skills related (i.e., behaviors and behavioral intentions), and attitudinal (Kalinoski et al., 2013).

The research on racial bias could be used to develop predictive measures that can determine whether there are significant and systematic differences in officers' reaction times and level of force toward citizens with varying stereotypical racial features. One such measure could be a training simulation that places an applicant in an ambiguous situation in which a citizen may potentially be perceived as a threat and then measures the decision making of the applicant based on stereotypicality as well as the speed at which the decision was made (similar to the shooter-bias scenarios, although other behavioral response options can also be used, such as physical takedowns of citizens). Such simulations, as well as shooter-bias simulations, could be implemented in training sessions to teach officers about race-based shooter biases. In such cases these exercises could be coupled with activities that help reduce the biases seen in the simulations.

In addition, I-O psychologists can work to expand the scope of officer diversity training to include information about implicit racial biases and their impact on behavior when needed. It is likely that some forces already incorporate such information, but in cases where they do not, this information would be valuable. It is important to ensure that training focuses on teaching officers to not only recognize cultural assumptions as stereotypes but also understand the nature of unconscious bias and how to recognize their own biases. Diversity training should include information concerning the realities and consequences of the tensions between officers and citizens (particularly minority citizens) in a way that clearly demonstrates its importance. This should stimulate insight into how these tensions influence citizens' perceptions, trust, and potential behavior toward officers, as well as insights for how to overcome negative perceptions and remain calm when appropriate.

In addition to sensitivity training, training that combines conflict resolution with racial bias reduction strategies would be beneficial in reducing some aggressive incidents between officers and citizens of color. Although conflict resolution training may be quite common, it is not always mandatory, and it may not always include an emphasis on race bias and tensions in this context. Citizens who are minorities may show increased levels of fear, anxiety, or agitation when they encounter police officers as a result of their perceptions of and experiences with prior victimization and their awareness of what they see as police harassment and brutality. Anxiety-ridden responses or stereotype-consistent behaviors from citizens also may be the result of the treatment they are experiencing from officers within a current 
interaction. That is, if Black citizens perceive that an officer is treating them in a manner that is overly hostile and based on race, they may indeed respond in an agitated, aggressive, or other negative manner, which in turn would likely lead to an escalation of conflict. Conflict resolution training designed to specifically deal with relations between officers and minority citizens could focus on de-escalating situations in nonviolent ways.

I-O psychologists could apply expert knowledge and experience to improve the execution and evaluation of these trainings. In terms of execution, greater guidance on delivery of the trainings can be given to ensure that content is delivered consistently and effectively so as to maximize learning and transfer of knowledge. Also, providing further validation evidence for the usefulness of diversity and cultural sensitivity training would bolster the call for such training to become a requirement for police departments. It may also increase the use of diversity sensitivity training, even when the law does not obligate officers to undergo this training. I-O psychologists also can help to identify other possible areas where additional officer training is needed by conducting training needs analyses. For example, the knowledge and skills taught in the police academy could be better aligned with those needed once on the job (Henson, Reyns, Klahm, \& Frank, 2010).

Although training should help reduce some of the expressions of racial bias in policing, it is possible that training on soft skills such as cultural sensitivity may fade over time, particularly in a high-stress, high-demand job such as law enforcement. To address this issue, I-O psychologists could conduct assessments to understand the dynamics that influence such fading effects and could work to develop systems that allow for systematic and periodic training related to diversity and cultural sensitivity. Further, needs analyses can be used to help identify the need for retraining, the frequency with which retraining should occur, and the resources needed to ensure that such an endeavor is more effective than costly.

\section{Performance Evaluation and Management}

A host of I-O research also focuses on performance appraisal and the evaluation process. Although it can be assumed that most law enforcement agencies use adequate measures to evaluate task performance, these measures may not include evaluations of behaviors that indicate racial bias. To address this, I-O psychologists should work with law enforcement to develop evaluation measures that clearly evaluate the fair treatment of citizens of all races. I-O psychologists could help to develop specific, observable, and measurable criteria with regard to displays of racial bias to accurately measure fair treatment. Including these critical performance criteria in evaluations would provide better identification of officers who may be more likely to use overly aggressive or potentially deadly force that is avoidable. Although individual 
incidents of excessive or fatal force are likely recorded and considered in performance evaluations, the potential racial bias within such incidents might not be reflected in an officer's evaluation if the performance evaluation system does not specifically account for bias. That is, the context of and pattern for displaying racial bias might be missed if performance evaluation systems do not explicitly include a measure of such bias.

Providing more formal evaluations of behaviors that are indicative of racial bias in typical and less critical situations (e.g., traffic stops) would help to monitor incidents and, over time, identify officers who routinely engage in activities reflective of racial bias (such as a disproportionate frequency of stopping and searching Black vs. White citizens). Providing more accurate and consistent accounts of biased behaviors in typical and frequent circumstances would help to prevent escalating patterns of bias-which ultimately can spin out of control in the form of larger, critical incidents. More consistent identification of racial bias would also send a clear message to officers that the organization does not condone racial bias in any form. In addition, such measures would help to identify officers who frequently exhibit racial biases with citizens, which is important for holding officers accountable and taking corrective action.

In addition to formal evaluations systems, I-O psychologists could also work to help develop and implement more ongoing, frequent feedback mechanisms for tasks that are considered routine, such as traffic stops or responses to domestic disputes. These feedback mechanisms could be formal and/or informal. The frequent nature of this process would allow for earlier detection of bias and could lead to more ongoing opportunities for development (vs. consequences) than annual evaluation systems. Feedback systems could be based on data from written reports, dash camera videos, body-mounted cameras, and other observations. Supervisors could review data from similar instances (e.g., traffic stops) involving citizens from various demographic backgrounds for a given officer and evaluate the officer's performance and outcomes in these instances. This process would enable officers and their supervisors to detect any potential differences in behavior that occurred in similar interactions that might seem routine and not particularly aggressive (e.g., perhaps an officer is more likely to ask to search a car during a traffic stop of minority vs. nonminority citizens) but that might indicate racial bias.

In addition, in cases where officers work with a partner, the pair could be trained to perform abbreviated after-action reviews and short debriefing sessions after responding to incidents. In these sessions, it would be important to discuss the demographic characteristics of the citizen and how they may have influenced the interaction. Such frequent evaluations would yield earlier detection of potential biased treatment, would create more conscious 
thought about how and why one's interactions with minority citizens may be biased (e.g., an officer may think about what situations are more likely to induce bias), and would allow for a quick intervention that could ultimately thwart the use of unnecessary or unreasonable force or the escalation of situations involving minority citizens.

Practitioners can help in other areas of performance management. Some recent data suggest that officers in some police forces are rarely disciplined for citizen complaints (Williams, 2015). This lack of accountability sends a signal to officers that they can treat citizens in ways that may make them feel violated or uncomfortable without consequences. This may provide officers who engage in racially biased behaviors toward citizens with a belief that they have a license to continue to act in this way. I-O psychologists could work with police departments to develop clear policies regarding the consequences for officers who have displayed biased behaviors toward citizens and others. Such policies should provide clear rules and guidelines about what types of behaviors are considered biased and should clearly delineate the consequences for violations. Further, practitioners can work with supervisors and human resources partners to help develop action plans for how to implement disciplinary actions when officers have violated policies. The administration of consequences for violations must be consistent and in line with policies in order to develop performance standards, effect positive change, and create accountability for those who engage in biased behavior.

\section{Organizational Climate}

One factor that can contribute to the persistence of negative racial bias within a law enforcement organization is the extent to which the organizational climate supports such biases (through either actively condoning displays of bias or passively not condemning it). That is, if the organization climate is one that passively accepts or openly embraces these biases, then individual officers within this organization may feel more comfortable expressing such biases. A climate that condones racial bias may be one in which officers support or fail to condemn practices of racial profiling in daily tasks (e.g., traffic stops). In addition, racial biases can become part of the climate of the organization if incidents that may be seen as innocent, such as telling profane race-related jokes or using racially charged language, are not prohibited. Although such behaviors may not appear to be related to task performance, they can lead to social norms or standards of accepted behavior within the organization that lead to and/or bleed into task performance (e.g., using racially charged language when discussing or interacting with potential suspects). Indeed, as people look to others to help decide what behavior is acceptable, findings show that people in the presence of those who condone (vs. condemn) prejudice are more likely to express prejudicial attitudes 
(Zitek \& Hebl, 2007). Furthermore, research has shown that acceptance of disparaging humor, such as racially charged jokes, can fuel a tolerance for other forms of prejudicial expression and discriminatory behaviors (Ford \& Ferguson, 2004). In the context of law enforcement, officers in environments that condone (vs. condemn) prejudicial expression toward Black people and other minorities may be more likely to act in a discriminatory manner on the job.

On a positive note, normative information and behavior also can encourage positive behaviors. Findings suggest providing individuals with information that racial stereotyping is not normative can reduce stereotyping against others (Stangor, Sechrist, \& Jost, 2001; see also Zitek \& Hebl, 2007). Thus, changing the norms within an environment to be more positive should have similar influential effects to that of negative normative behavior. Some police departments are beginning to try to actively create normative environments that condemn biases, hate, and intolerance. For instance, police departments in San Francisco are asking officers to recite a pledge against intolerance and hate (Elias, 2016). The pledge was developed in part by an affinity group within the department as a way to combat racism and reduce tensions between officers and community members. Such steps may seem small, but they have the potential to lead to positive behavior. I-O psychologists can work with departments to simply educate officers and other members of the organization about the power of normative influence and about how to create positive change in normative behavior.

I-O psychologists have conceptualized "diversity climate" to account for how race relates to organizational culture (for examples see Gonzalez \& DeNisi, 2009; McKay et al., 2007; Mor Barak, Cherin, \& Berkman, 1998). Diversity climate is a more specific measure of organizational climate that refers to "employees' shared perceptions of the policies, practices, and procedures that implicitly and explicitly communicate the extent to which fostering and maintaining diversity and eliminating discrimination is a priority in the organization" (Gelfand, Nishii, Raver, \& Schneider, 2005, p. 104). Within law enforcement, I-O psychologists could conduct climate studies to measure factors such as acceptance of racial bias within specific law enforcement agencies. Some useful measures already have been developed to measure culture and climate for inclusion (for example, see Mor Barak et al., 1998). To effect positive change in this area, I-O psychologists could begin with developed and validated measures to assess the current organizational climate regarding the nature of race relations within police departments. Additional measurement tools that specifically assess climate for racial diversity could be developed to supplement those measures.

In addition to directly measuring diversity climate within law enforcement organizations, new measurement tools could be developed that 
explicitly capture how community members' perceptions might influence the diversity climate within law enforcement organizations. It is quite likely that interactions with citizens in the field influence an individual officer's mood, attitude, and behavior, which can in turn influence the mood and behaviors of others and the overall diversity climate. Results from climate surveys could be used to develop interventions and change-management programs to reduce racial bias (or other biases) when organizations exhibit significant levels of bias. Some law enforcement organizations have begun to institute policy changes with regard to issuing body cameras to officers in an attempt to create fairer treatment of citizens regardless of race (Kahn \& Martin, 2016). These devices should influence the organizational climate, particularly within organizations where officers do not believe there is a high level of bias-based policing. I-O psychologists can work with such organizations to help organizations adjust to how organizational changes might influence officers to ensure that such changes do not have negative effects on officers' job attitudes and behavior.

Finally, policies and procedures that foster more positive diversity climates could be developed (including specific diversity training). In cases where changes are necessary, I-O psychologists could work with departments to determine the best way to communicate and implement changes.

\section{Leadership}

Management buy in and support are important factors in successfully implementing new policies or changes in organizations and may be particularly critical in reducing discrimination (Balogun \& Johnson, 2004; Maitlis, 2005; Ruggs, Martinez, \& Hebl, 2011). In agencies in which racial biases have been identified, it is crucial to have management support in implementing policies to combat the presence and consequences of these biases. Understanding and managing the dynamics of leadership in law enforcement agencies is crucial to making positive changes regarding systematic racial biases instituted by officers within these agencies. As discussed in sections above, I-O psychologists could work with police departments to ensure that leaders have the right tools for dealing with racial discrimination in terms of performance management, policies and procedures, training, organization climate, and other talent management tools.

I-O psychologists can help to expand leadership development programs in law enforcement to include racial sensitivity modules. These programs could provide leaders with the diagnostic skills needed to assess situations in terms of weighing racial bias against behaviors that fall within protocol and procedure. Leaders could gain skills in understanding how racial biases have influenced situations and the chain of unintended consequences. These 
programs would equip management with tools to effectively deal with racial biases when they arise.

\section{Community Relations}

Problems with individual police officers or some police departments do not reflect the entire law enforcement community, but the number of racial incidents across the United States points to a systemic issue. Racial disparities in law enforcement are abundant (Goff \& Kahn, 2012). The systemic issue is exacerbated by generally poor perceptions of the police, which are often particularly prevalent in minority, low-income communities. Support for this has been shown empirically. Across 92 studies, Black and other racial minorities reported significantly more negative attitudes and perceptions concerning police than did Whites (Peck, 2015). Negative perceptions of officers sometimes exist even when bias-based policing is not occurring. This appears, at least in part, to be the result of emotional contagion resulting from the farreaching impact of fatal events, such as the shooting of Michael Brown, that shake the trust of citizens and confirm beliefs and fears about police brutality and bias-based policing. Even in instances where unnecessary force is not involved, minorities may still have fears about police due to past (and sometimes present) policies that appear to unjustly target minorities, such as stop-and-frisk policies. One potential solution to negative perceptions of police is community policing, which seeks to enhance relationships between law enforcement and the community. Community policing also gives police a greater sense of community service and provides more interaction between officers and the communities in which they serve (Greene, 2000).

To further the mission of community policing, I-O psychologists can help to develop and administer assessments for community members that gauge their perceptions of local law enforcement (e.g., level of trust). These assessments should take a community-level approach as a means to understand the overall community climate as well as differences in perceptions across different demographic groups. If some groups within the community have more negative perceptions than others do, then I-O psychologists can work with law enforcement officials to determine why these differences are present. Is it the case that some members of the community perceive negative bias toward their community from police, and if so why? Do some groups have inaccurate or incomplete information about things that officers have done in the community? Once there is a diagnosis, I-O psychologists could work with police departments to develop programs to enhance community members' perceptions and gain trust. In addition, longitudinal measures could be obtained to track community climate changes and progress toward more positive climates as well as ensure more accountability from police departments. 


\section{The Role of I-O Psychology in Preventing Future Fires}

In addition to taking immediate action to extinguish current flames of tension and conflict between police departments and communities, I-O psychologists can play a role in helping to prevent future fires by conducting more research in areas related to racial biases in policing. A more complete understanding of the factors that predict police officer expression of racial bias, as well as the identification of factors that aid in the suppression of these expressions, would contribute to the overall mission of stopping excessive or unwarranted police aggression toward citizens while also building and restoring trust in law enforcement from skeptical citizens. Future research could take a deeper look into factors that influence officer bias. Previous research on prejudice has shown that some ideological beliefs and individual difference characteristics such as right-wing authoritarianism (see Altemeyer \& Hunsberger, 1992) are correlated with prejudicial attitudes. In addition to such beliefs, there are other cognitive and attitudinal factors that influence officers' perceptions of minority citizens. Future research should examine potential individual difference characteristics that may exacerbate expressions of racial bias from officers.

Future research should also examine other variables in addition to bias that may lead to unnecessary use of force by officers or differential treatment of citizens based on race. Two such factors that may influence expressions of racial bias are the crime rate in and demographic makeup of the community in which the officer works. An officer who works in a predominately minority community that has a high crime rate may see stereotypes about minorities and violence confirmed more often and, therefore, may be more likely to express racial bias than an officer in a largely White community with a low crime rate. However, if officers in predominately minority communities are motivated to get to know members of the community in which they serve, they may be more empathetic. Further, they should be less likely to exhibit racial bias even if there is a high crime rate because they are able and willing to perceive the people they interact with as individuals deserving of safety and respect and not as stereotypical representations of the group in which those individuals belong.

In addition to examining how individual- and societal-level factors may influence the expression of racial bias by officers, future research should examine how situational factors may influence bias expression and excessive use of force by police officers. That is, are there specific conflict triggers that lead to officers' biased behavior? One trigger point is likely citizens' behavior toward officers. If an officer perceives negativity or resistance from a citizen during an interaction, this will likely influence the officer's behavior such that the officer is more forceful and assertive in the situation. This type of response would be appropriate to maintain control of a situation; however, the 
level of forcefulness may tip toward excessive, based on citizen demographics. Specifically, it is possible that some officers are more sensitive to certain types of behaviors when displayed by minorities versus nonminorities and therefore respond differently to the same behaviors displayed by individuals from different racial groups. Research should explore differences in trigger points as a function of the citizen's race, as well as explore ways to potentially increase officers' awareness of these triggers.

Finally, we recommend that future research examine additional interventions that can be used to reduce and prevent the expression of racial bias and biased-based policing as well as the perception of these biases. Greater research is needed in the overall area of diversity training to understand the long-term outcomes associated with training and the effect of diversity training on behavior in the field. Future research should take a longitudinal approach to examining the outcomes of trainings that focus on reducing racial bias. In addition, research should examine the effectiveness of different interventions geared at community policing and creating more positive interactions between citizens and police in communities where trust is broken and tensions are high. Some research in this area is underway in various fields outside of psychology such as criminal justice, law, and sociology; therefore, an interdisciplinary approach to interventions would be most appropriate and beneficial. We encourage greater interdisciplinary work between I-O psychologists and experts from other fields to help take a more holistic approach to the problems occurring with racial bias in policing and the ways to reduce such problems.

\section{Conclusion}

Continued incidents involving potentially excessive police aggression against unarmed minority citizens points to systematic individual-, occupational-, and organizational-level issues within law enforcement institutions that need to be addressed. We have highlighted several areas in which I-O psychologists are well positioned to be a part of the solution. The field of I-O has many resources that can be useful in reducing systematic racial bias in law enforcement. We send a call to action to both researchers and practitioners to use these resources to help douse the flames of racebased responses to citizens that are occurring across the country (and prevent these fires from persisting). To this point, there have been some attempts to address individual incidents; however, the nature of the racial bias that accounts for some of these incidents will require truly systemic and systematic interventions that examine and address psychological processes at the individual, organizational, and societal levels. Thus, we recommend greater empirical research within the areas we have discussed in order to validate, implement, and evaluate evidence-based management programs regarding 
racial bias in policing. Further, I-O practitioners must continue to proactively seek greater opportunities to engage in problem solving and solution building for police agencies with regard to racial biases. Only then can we attempt to combat widespread racial bias, profiling, and violence across United States communities.

\section{References}

Aamodt, M. G. (2004). Research in law enforcement selection. Boca Raton, FL: Brown Walker Press.

Allport, G. W., \& Postman, L. J. (1947). The psychology of rumor. New York, NY: Russell \& Russell.

Alpert, G., Dunham, R., \& Smith, M. (2007). Investigating racial profiling by the MiamiDade police department: A multimethod approach. Criminology \& Public Policy, 6(1), 25-55. doi:10.1111/j.1745-9133.2007.00420.x

Altemeyer, B., \& Hunsberger, B. (1992). Authoritarianism, religious fundamentalism, quest, and prejudice. The International Journal for the Psychology of Religion, 2, 113-133. doi:10.1207/s15327582ijpr0202_5

Ashkenas, J., \& Park, H. (2015, April 8). The race gap in America's police departments. The New York Times. Retrieved from http://www.nytimes.com/interactive/ 2014/09/03/us/the-race-gap-in-americas-police-departments.html?_r=0

Avery, D. R., Mckay, P. F., Tonidandel, S., Volpone, S. D., \& Morris, M. A. (2012). Is there method to the madness? Examining how racioethnic matching influences retail store productivity. Personnel Psychology, 65(1), 167-199. doi:10.1111/ j.1744-6570.2011.01241.x

Balogun, J., \& Johnson, G. (2004). Organizational restructuring and middle manager sensemaking. Academy of Management Journal, 47(4), 523-549. doi:10.2307/20159600

Barrick, M. R., \& Mount, M. K. (1991). The Big Five personality dimensions and job performance: A meta-analysis. Personnel Psychology, 44, 1-26. doi:10.1111/ j.1744-6570.1991.tb00688.x

Berner, J. G. (2010). Pre-offer personality testing in the selection of entry-level California peace officers: A technical report prepared for the California Commission on Peace Officer Standards and Training. Retrieved from http://lib.post.ca.gov/Publications/ technical_report.pdf

Bureau of Justice Statistics. (2011). Arrest-related deaths, 2003-2009. Retrieved from http://www.bjs.gov/index.cfm?ty=pbdetail\&iid $=4943$

Correll, J., Hudson, S. M., Guillermo, S., \& Ma, D. S. (2014). The police officer's dilemma: A decade of research on racial bias in the decision to shoot. Social and Personality Psychology Compass, 8(5), 201-213. doi:10.1111/spc3.12099

Correll, J., Park, B., Judd, C. M., \& Wittenbrink, B. (2002). The police officer's dilemma: Using ethnicity to disambiguate potentially threatening individuals. Journal of Personality and Social Psychology, 83(6), 1314-1329. doi:10.1037/0022-3514.83.6.1314

Correll, J., Park, B., Judd, C. M., Wittenbrink, B., Sadler, M. S., \& Keesee, T. (2007). Across the thin blue line: Police officers and racial bias in the decision to shoot. Journal of Personality and Social Psychology, 92(6), 1006-1023. doi:10.1037/0022-3514.83.6.1314

Correll, J., Urland, G. L., \& Ito, T. A. (2006). Event-related potentials and the decision to shoot: The role of threat perception and cognitive control. Journal of Experimental Social Psychology, 42(1), 120-128. doi:10.1016/j.jesp.2005.02.006 
Craig, R. J. (2005). Personality-guided forensic psychology. Washington, DC: American Psychological Association. doi:10.1037/10829-000

Detrick, P., \& Chibnall, J. T. (2006). NEO PI-R personality characteristics of highperforming entry-level police officers. Psychological Services, 3(4), 274-285. doi:10.1037/1541-1559.3.4.274

Devine, P. G. (1989). Stereotypes and prejudice: Their automatic and controlled components. Journal of Personality and Social Psychology, 56(1), 5-18. doi:10.1037/ 0022-3514.56.1.5

Dixon, T., Schell, T. L., Giles, H., \& Drogos, K. L. (2008). The influence of race in police-civilian interactions: A content analysis of videotaped interactions taken during Cincinnati police traffic stops. Journal of Communication, 58(3), 530-549. doi:10.1111/j.1460-2466.2008.00398.x

Dovidio, J. F., \& Gaertner, S. L. (2000). Aversive racism and selection decisions: 1989 and 1999. Psychological Science, 11, 319-323. doi:10.1111/1467-9280.00262

Duncan, B. L. (1976). Differential social perception and attribution of intergroup violence: Testing the lower limits of stereotyping of Blacks. Journal of Personality and Social Psychology, 34, 590-598. doi:10.1037/0022-3514.34.4.590

Eberhardt, J. L., Goff, P. A., Purdie, V. J., \& Davies, P. G. (2004). Seeing Black: Race, crime, and visual processing. Journal of Personality and Social Psychology, 87(6), 876-893. doi:10.1037/0022-3514.87.6.876

Elias, P. (2016). San Francisco police recite pledge to root out intolerance. Associated Press. Retrieved from http://www.ocregister.com/articles/officers-702123-policepledge.html

Ford, T. E., \& Ferguson, M. A. (2004). Consequences of disparagement humor: A prejudiced norm theory. Personality and Social Psychology Review, 8(1), 79-94. doi:10.1207/ S15327957PSPR0801_4

Garza, A., Tometi, O., \& Cullors, P. (2012). A HerStory of the \#BlackLivesMatter movement. Retrieved from http://blacklivesmatter.com/herstory/

Gelfand, M. J., Nishii, L. H., Raver, J., \& Schneider, B. (2005). Discrimination in organizations: An organizational level systems perspective. In R. Dipboye \& A. Colella (Eds.), Discrimination at work: The psychological and organizational bases (pp. 89-116). Mahwah, NJ: Erlbaum.

Goff, P. A., Jackson, M. C., Di Leone, B. A. L., Culotta, C. M., \& DiTomasso, N. A. (2014). The essence of innocence: Consequences of dehumanizing Black children. Journal of Personality and Social Psychology, 106(4), 526-545. doi:10.1037/a0035663

Goff, P. A., \& Kahn, K. B. (2012). Racial bias in policing: Why we know less than we should. Social Issues and Policy Review, 6, 177-210. doi:10.1111/j.1751-2409.2011.01039.x

Golub, A., Johnson, B. D., \& Dunlap, E. (2007). The race/ethnicity disparity in misdemeanor marijuana arrests in New York City. Criminology \& Public Policy, 6(1), 131164. doi:10.1111/j.1745-9133.2007.00426.x

Gonzalez, J. A., \& DeNisi, A. S. (2009). Cross-level effects of demography and diversity climate on organizational attachment and firm effectiveness. Journal of Organizational Behavior, 30(1), 21-40. doi:10.1002/job.498

Gove, T. G. (2011, October). Implicit bias and law enforcement. The Police Chief: The Professional Voice of Law Enforcement. Retrieved from http://www.policechiefmagazine. org/magazine/index.cfm?fuseaction=display_arch\&article_id=2499\&issue_id= 102011

Greene, J. R. (2000). Community policing in America: Changing the nature, structure, and function of the police. Criminal Justice, 3, 299-370. 
Greenwald, A. G., Oakes, M. A., \& Hoffman, H. G. (2003). Targets of discrimination: Effects of race on responses to weapon holders. Journal of Experimental Social Psychology, 39(4), 399-405. doi:10.1016/S0022-1031(03)00020-9

Henson, B., Reyns, B. W., Klahm, C. F., \& Frank, J. (2010). Do good recruits make good cops? Problems predicting and measuring academy and street-level success. Police Quarterly, 13, 5-26. doi:10.1177/1098611109357320

Horwitz, S. (2015, February 12). FBI director acknowledges "hard truths" about racial bias in policing. The Washington Post. Retrieved from https://www.washingtonpost.com/ world/national-security/fbi-director-acknowledges-hard-truths-about-racial-bias-inpolicing/2015/02/12/023c6c6e-b2c6-11e4-854b-a38d13486ba1_story.html

Hough, L. M. (2002). Hiring in the spirit of service: Definitions, possibilities, evidence, \& recommendations. Prepared for Community Policing Consortium, Office of Community Oriented Policing Services, U.S. Department of Justice. Washington, DC.

Johnson, J. D., Whitestone, E., Jackson, L. A., \& Gatto, L. (1995). Justice is still not colorblind: Differential racial effects of exposure to inadmissible evidence. Personality and Social Psychology Bulletin, 21, 893-898. doi:10.1177/0146167295219003

Kahn, K. B., \& Davies, P. G. (2011). Differentially dangerous? Phenotypic racial stereotypicality increases implicit bias among ingroup and outgroup members. Group Processes \& Intergroup Relations, 14(4), 569-580. doi:10.1177/1368430210374609

Kahn, K. B., \& Martin, K. D. (2016). Policing and race: Disparate treatment, perceptions, and policy responses. Social Issues and Policy Review, 10, 82-121. doi:10.1111/sipr.12019

Kalinoski, Z. T., Steele-Johnson, D., Peyton, E. J., Leas, K. A., Steinke, J., \& Bowling, N. A. (2013). A meta-analytic evaluation of diversity training outcomes. Journal of Organizational Behavior, 34(8), 1076-1104. doi:10.1002/job.1839

Maddox, K. B. (2004). Perspectives on racial phenotypicality bias. Personality and Social Psychology Review, 8, 383-401. doi:10.1207/s15327957pspr0804_4

Maitlis, S. (2005). The social processes of organizational sensemaking. Academy of Management Journal, 48, 21-49. doi:10.5465/AMJ.2005.15993111

McKay, P. F., Avery, D. R., Tonidandel, S., Morris, M. A., Hernandez, M., \& Hebl, M. R. (2007). Racial differences in employee retention: Are diversity climate perceptions the key? Personnel Psychology, 60, 25-62. doi:10.1002/job.4030140107

Mekawi, Y., \& Bresin, K. (2015). Is the evidence from racial bias shooting task studies a smoking gun? Results from a meta-analysis. Journal of Experimental Social Psychology, 61, 120-130. doi:10.1016/j.jesp.2015.08.002

Mor Barak, M. E., Cherin, D. A., \& Berkman, S. (1998). Organizational and personal dimensions in diversity climate: Ethnic and gender differences in employee perceptions. Journal of Applied Behavioral Science, 34, 82-104. doi:10.1177/0021886398341006

Payne, B. K. (2001). Prejudice and perception: The role of automatic and controlled processes in misperceiving a weapon. Journal of Personality and Social Psychology, 81(2), 181-192. doi:10.1037/0022-3514.81.2.181

Peck, J. H. (2015). Minority perceptions of the police: A state-of-the-art review. American Journal of Police, 38, 173-203. doi:10.1108/PIJPSM-01-2015-0001

Plant, E. A., \& Peruche, B. M. (2005). The consequences of race for police officers' responses to criminal suspects. Psychological Science, 16(3), 180-183. doi:10.1111/j.0956-7976.2005.00800.x

Quillian, L., \& Pager, D. (2001). Black neighbors, higher crime? The role of racial stereotypes in evaluations of neighborhood crime. American Journal of Sociology, 107(3), 717-767. doi: $10.1086 / 338938$ 
Rubin, M., \& Badea, C. (2012). They're all the same! . . but for several different reasons: A review of the multicausal nature of perceived group variability. Current Directions in Psychological Science, 21, 367-372. doi:10.1177/0963721412457363

Ruggs, E. N., Martinez, L. R., \& Hebl, M. R. (2011). How individuals and organizations can reduce interpersonal discrimination. Social and Personality Psychology Compass, 5, 2942. doi:10.1111/j.1751-9004.2010.00332.x

Sagar, H. A., \& Schofield, J. W. (1980). Racial and behavioral cues in Black and White children's perceptions of ambiguously aggressive acts. Journal of Personality and Social Psychology, 39(4), 590-598. doi:10.1037/0022-3514.39.4.590

Sommers, S. R., \& Ellsworth, P. C. (2001). White juror bias: An investigation of prejudice against Black defendants in the American courtroom. Psychology, Public Policy, and Law, 7(1), 201-229. doi:10.1037/1076-8971.7.1.201

Stangor, C., Sechrist, G. B., \& Jost, J. T. (2001). Changing racial beliefs by providing consensus information. Personality and Social Psychology Bulletin, 27(4), 486-296. doi:10.1177/0146167201274009

Ungerleider, C. S., \& McGregor, J. (1993). Training police for intercultural sensitivity: A critical review and discussion of the research. Canadian Public Administration, 36(1), 7789. doi:10.1111/j.1754-7121.1993.tb02167.x

U.S. Department of Justice. (2014). Guidance for federal law enforcement agencies regarding the use of race, ethnicity, gender, national origin, religion, sexual orientation, or gender identity. Retrieved from http://www.justice.gov/sites/default/files/ag/pages/ attachments/2014/12/08/use-of-race-policy.pdf

Williams, T. (2015, November 18). Chicago rarely penalizes officers for complaints, data shows. The New York Times. Retrieved from http://www.nytimes.com/2015/11/ 19/us/few-complaints-against-chicago-police-result-in-discipline-data-shows.html? smid=nytcore-ipad-share\&smprod=nytcore-ipad)\&_r=0

Yang, G. S., Gibson, B., Lueke, A. K., Huesmann, L. R., \& Bushman, B. J. (2014). Effects of avatar race in violent video games on racial attitudes and aggression. Social Psychological \& Personality Science, 5, 698-704. doi:10.1177/1948550614528008

Zitek, E. M., \& Hebl, M. R. (2007). The role of social norm clarity in the influenced expression of prejudice over time. Journal of Experimental Social Psychology, 43(6), 867-876. doi:10.1016/j.jesp.2006.10.010 